\title{
Treatment of Lupus Nephritis from Iranian Traditional Medicine and Modern Medicine Points of View: A Comparative Study
}

\author{
Yasaman Vahedi-Mazdabadi $\mathbb{i}^{1}$ and Mina Saeedi $\mathbb{i}^{1,2}$ \\ ${ }^{1}$ Persian Medicine and Pharmacy Research Center, Tehran University of Medical Sciences, Tehran, Iran \\ ${ }^{2}$ Medicinal Plants Research Center, Faculty of Pharmacy, Tehran University of Medical Sciences, Tehran, Iran \\ Correspondence should be addressed to Mina Saeedi; m-saeedi@tums.ac.ir
}

Received 14 December 2020; Revised 14 August 2021; Accepted 24 September 2021; Published 9 November 2021

Academic Editor: Muhammad Nabeel Ghayur

Copyright (c) 2021 Yasaman Vahedi-Mazdabadi and Mina Saeedi. This is an open access article distributed under the Creative Commons Attribution License, which permits unrestricted use, distribution, and reproduction in any medium, provided the original work is properly cited.

\begin{abstract}
Objective. Nephritis or kidney inflammation is characterized as one of the most common renal disorders leading to serious damage to the kidneys. Nephritis, especially lupus nephritis (LN), has remained as the main cause of chronic renal failure which needs serious therapeutic approaches such as dialysis and kidney transplant. Heredity, infection, high blood pressure, inflammatory diseases such as lupus erythematosus and inflammatory bowel disease, and drug-related side effects are known as the main causes of the disease. According to Iranian traditional medicine (ITM), infectious diseases and fever are the main reasons of nephritis, which is called "Varam-e-Kolye" (VK). Results. There are various plant-based remedies recommended by ITM for the treatment of nephritis, as discussed herein, comparing with those available in the modern medicine. There is no definite cure for the treatment of nephritis, and immunosuppressive drugs such as corticosteroids and nonsteroidal anti-inflammatory drugs, antibiotics, diuretics, analgesics, and finally dialysis and kidney transplantation are usually used. Based on the efficacy of medicinal plants, jujube (Ziziphus jujuba), almond (Prunus amygdalus), pumpkin seeds (Cucurbita pepo), purslane (Portulaca oleracea), and fig (Ficus carica) were found to be effective for the treatment of kidney inflammation in ITM. Conclusion. Considering the fact that there is no efficient strategy for the treatment of nephritis, use of herbal medicine, particularly based on the fruits or nuts that have been safely used for several years can be considered as a versatile supplement along with other therapeutic methods.
\end{abstract}

\section{Introduction}

Nephritis is characterized as the inflammation of kidney, affecting the glomerulus, tubule, or interstitial renal tissues $[1,2]$. Although lots of therapeutic approaches have been recently developed for the treatment of various diseases, nephritis has still remained as the main cause of chronic kidney failure leading to significant financial burden on the societies [3]. Nephritis was ranked as 17 th principal cause of death in 2002. Moreover, the number of cases of nephritis is increasing and it is expected to be the 13th leading cause of death in 2030 [4]. Various factors such as heredity including APOL1 gene variations [5], infection [6], hypertension [7], inflammatory diseases such as systemic lupus erythematosus (SLE) [8] and inflammatory bowel disease [9], drug-related side effects, and unknown causes [10] have been involved in the pathogenesis of the disease. Among these factors, SLE, simply called lupus, is one of the most significant causes of nephritis, which is known as lupus nephritis (LN). In fact, sedimentation of inflammatory mediators in the kidney tissue as the main result of SLE leads to glomerulonephritis and tubulointerstitial inflammation $[11,12]$.

Various studies have confirmed that the activation of nuclear factor kappa B (NF- $\kappa \mathrm{B}$ ) signal pathway via upregulation of proinflammatory mediators such as cyclooxygenase-2 (COX-2) and tumor necrosis factor- $\alpha$ (TNF- $\alpha$ ) is responsible for LN [13]. Also, it has been demonstrated that B- and T-cell hyperactivity [14], increased T helper 1 (Th1) and T helper 17 (Th17) cytokines $[15,16]$, activation of JAK/STAT-3 signaling [17], elevation of anti-doublestranded DNA (anti-dsDNA) antibodies [12], autoantibodies against proteins involved in clearing extracellular 
nuclear material such as pentraxin 3 or C-reactive protein [18], interleukin-6 (IL-6), interleukin-17 (IL-17), interleukin-23 (IL-23), TNF- $\alpha[19,20]$, oxidative stress [14], decreased $\mathrm{T}$ regulator cells (Tregs) [21], and complement system [22] play important roles in the pathophysiology of LN.

LN is currently treated with an immunosuppressive regimen including induction therapy and then a maintenance immunosuppression phase $[8,18]$. However, despite using aggressive therapies, the outcome and prognosis of LN have not been resolved since the 1980s [8] and up to $50 \%$ of patients encounter organ damage and end-stage renal disease (ESRD) $[8,18]$. Some of these difficulties are indirectly associated with side effects of therapy [23, 24]. Furthermore, immunosuppressive drugs have shown severe adverse effects and a great number of patients have been prohibited to consume them [25]. Although novel approaches including anti-CD20 (B-lymphocyte antigen CD20) antibodies and calcineurin inhibitors have shown encouraging results, their long-term benefit/risk ratios have not been specified [26]. Hence, it would be desirable to provide treatments based on societal dietary and food with no side effects [27]. In fact, some of the foodstuffs can be used as functional food in the treatment of this disease [28].

Traditional medicine, profiting from medicinal plants and dietary strategies, has played a significant role in the treatment of different diseases such as kidney diseases [29-31]. In ITM, nephritis has been known as "Varam-eKolye" (VK) [32]. It is believed that infectious diseases, fever, strike, severe pressure on the kidney, urinary retention, scratch caused by kidney stones, increased blood volume, and untreated disease background are the main causes of nephritis or kidney swelling [32-34]. ITM has recommended safe herbal remedies for the treatment nephritis, most of which can be used in everyday life [31-34]. However, it is worth mentioning that some plants need a special attention to avoid severe problems such as toxicity [35-37].

In this review, treatment of nephritis has been discussed from the ITM point of view comparing with modern medicine, and moreover, some renal adverse effects related to medicinal plants were discussed.

\section{Methods}

Herein, credible Iranian traditional medicine resources such as "Qanun-fil-Tibb" (the Law of Medicine), "Exir-e-Azam" (Great Elixir), "Makhzan-al-Advieh" (the Storehouse of Medicaments), and "Tibb-e-Akbari" (Akbar's medicine) were studied using keywords including "varam" and "kolye". Also, recent developments were reviewed in modern medicine using search engines such as Google Scholar, PubMed, Scopus, SID, and Iranmedex using keywords such as "inflammation + kidney," "nephritis," "lupus nephritis," "systemic lupus erythematosus," "medicinal plant," "nephropathy," "nephrotoxicity," "hyperkalemia," "hyperphosphatemia," "plant-based diets," "NF-kB," "nutraceutical," and "treatment" without time or language restrictions. Materials related to study criteria were extracted and analyzed in a comprehensive manner.

\section{Results}

According to the World Health Organization (WHO) or the International Society of Nephrology/Renal Pathology Society (ISN/RPS) class III and upper advances to ESRD, LN or kidney inflammation induced by SLE is described as one of the most common renal diseases [38-40]. Although the disease affects all parts of the kidney, the clinical evidence indicated that the glomerulus has the highest amounts of deposition of immune complexes and is involved in inflammation and formation of lesions [40-42] (Table 1).

At present, there is no definite cure for the treatment of nephritis in modern medicine [8], and usually, immunosuppressive drugs such as corticosteroids $[8,25]$ and nonsteroidal anti-inflammatory [25], renin-angiotensinaldosterone system (RAAS) blockade [41], antibiotics [40], diuretics [43], dialysis [38, 44], and kidney transplantation [45] are recommended. However, in the early stages of LN including class I and II, no therapy is recommended by the American College of Rheumatology (ACR) guideline. The European LeagueAgainst Rheumatism and European Renal Association-European Dialysis and Transplant Association (EULAR/ERA-EDTA) suggested low to moderate doses of oral steroid agents which cause moderate proteinuria and glomerular hematuria $[18,41,46,47]$. It should be noted that 5-20\% patients with LN even with immunosuppressive therapy develop ESRD within 10 years [43]. Therefore, developing an efficient therapy for the treatment of inflammation of kidneys is highly in demand. In this regard, herbal remedies recommended by ITM have attracted lots of attention as the versatile strategy for the treatment of inflammation of kidneys (Table 2). However, some adverse effects demonstrated by some plants should not be forgotten (Table 3) [2, 83]. Also, special attention should be paid to the probable interaction of some herbs and different medications used by patients $[83,90-93]$. Some plants have a significant amount of potassium, which can cause hyperkalemia (potassium > $5.5 \mathrm{mmol} / \mathrm{l})$ in patients. Hence, the potassium content of these plants should also be considered [83, 94, 95] (Table 4).

\subsection{Plants with Renoprotective Effects}

3.1.1. Anethum graveolens. A. graveolens, known as sheviid in ITM, has been widely utilized to reduce renal swelling $[32,33]$. Khalil et al. indicated that oral ingestion of alcoholic extract of $A$. graveolens seeds in diabetic treated animals by alloxan diminished serum urea and creatinine and increased the serum glutathione concentration [48]. Kim et al. showed that the methanolic extract of A. graveolens flowers suppressed inducible nitric oxide synthase (iNOS) and inhibited NF- $\kappa \mathrm{B}$ activity via inhibiting the phosphorylation of serine/ threonine kinase 1 (Akt) in lipopolysaccharide (LPS)stimulated RAW 264.7 cells. Thus, it has an anti-inflammatory effect on LPS-stimulated RAW 264.7 cells [49].

3.1.2. Carum carvi. C. carvi seeds, known as zeerah-siyah in ITM, have been used to treat kidney swelling [33]. Sadiq et al. reported that the aqueous extract of C. carvi seeds 
TABLE 1: International Society of Nephrology/Renal Pathology Society (ISN/RPS) 2003 classification of lupus nephritis [39].

Class I

Class II

Class III

III (A)

III $(\mathrm{A} / \mathrm{C})$

III (C)

Class IV

IV (A)

IV $(\mathrm{A} / \mathrm{C})$

IV (C)

Class V

Class VI
Minimal mesangial LN

Mesangial proliferative LN

Focal LN (50\% of glomeruli)

Active lesions

Active and chronic lesions

Chronic lesions

Diffuse LN (50\% glomeruli)

Diffuse segmental (IV-S) or global (IV-G) LN

Active lesions

Active and chronic lesions

Chronic lesions

Membranous LN

Advanced sclerosing LN (90\% globally sclerosed glomeruli without residual activity)

TABLE 2: Plants used in the treatment of lupus nephritis in Iranian traditional medicine.

\begin{tabular}{|c|c|c|c|c|c|c|c|}
\hline Species & $\begin{array}{c}\text { English } \\
\text { name }\end{array}$ & $\begin{array}{c}\text { Iranian } \\
\text { name }\end{array}$ & Family & $\begin{array}{l}\text { Parts } \\
\text { used }\end{array}$ & Extract & Activity & Reference \\
\hline A. graveolens & Dill & Sheviid & Apiaceae & Seeds & Alcoholic extract & $\begin{array}{l}\text { Decrease in serum urea and } \\
\text { creatinine and increase in serum } \\
\text { glutathione concentration }\end{array}$ & {$[48,49]$} \\
\hline C. carvi & Caraway & $\begin{array}{l}\text { Zeerah- } \\
\text { siyah }\end{array}$ & Apiaceae & Seeds & Aqueous extract & Renoprotective & {$[50-52]$} \\
\hline C. sativum & Coriander & Geshniz & Apiaceae & Leaves & Ethyl acetate & $\begin{array}{c}\text { Nephroprotective potential } \\
\text { suppressing NF- } \kappa \text { B activation } \\
\text { and MAPK signal transduction } \\
\text { pathway }\end{array}$ & [53-56] \\
\hline C. pepo & Pumpkin & Kadoo & Cucurbitaceae & Seeds & & Renoprotective & {$[57]$} \\
\hline C. oblonga & Quince & Behi & Rosaceae & Fruits & Aqueous extract & $\begin{array}{c}\text { Reducing serum urea and } \\
\text { creatinine; reduction of IFN-g, } \\
\text { IL-2, ERK1/2, AKTa, NF- } \kappa \mathrm{B} \text {, } \\
\mathrm{NO} \text {, iNOS }\end{array}$ & {$[58,59]$} \\
\hline F. carica & Fig & Anjir & Moraceae & Fruits & $\begin{array}{l}\text { Hydroalcoholic } \\
\text { extract }\end{array}$ & $\begin{array}{c}\text { Nephroprotective activity } \\
\text { decreasing inflammatory } \\
\text { mediators such as TNF- } \alpha \text {, IL-6, } \\
\text { COX-2, and PGE-2 }\end{array}$ & {$[60,61]$} \\
\hline L. usitatissimum & Flaxseed & $\begin{array}{l}\text { Bazr-e- } \\
\text { katan }\end{array}$ & Linaceae & Seeds & Ground flaxseed, oil & Protective effect on renal injury & {$[62,63]$} \\
\hline M. officinalis & $\begin{array}{l}\text { Lemon } \\
\text { balm }\end{array}$ & Badranjboya & Lamiaceae & Leaves & $\begin{array}{l}\text { Aqueous extract } \\
\text { Ethanolic extract }\end{array}$ & $\begin{array}{c}\text { Nephroprotective and anti- } \\
\text { inflammatory effects reducing } \\
\text { the expressions of NF- } \kappa \text { B, TNF- } \\
\alpha \text {, and COX- } 2\end{array}$ & {$[64,65]$} \\
\hline P. amygdalus & Almond & Badam & Rosaceae & Kernels & $\begin{array}{l}\text { Hexane-isopropyl } \\
\text { alcohol extract, } \\
\text { ethanolic extract }\end{array}$ & $\begin{array}{c}\text { Renoprotective effect, } \\
\text { diminishing serum uric acid }\end{array}$ & [66-68] \\
\hline Z. jujuba Mill. & Jujube & Onab & Rhamnaceae & Fruits & $\begin{array}{l}\text { Aqueous extract } \\
\text { injection, a patent } \\
\text { herbal drug } \\
\text { decoction }\end{array}$ & $\begin{array}{c}\text { Reducing nephrotoxicity } \\
\text { induced by ibuprofen, } \\
\text { downregulated protein levels of } \\
\text { TGF- } \beta 1 \text {, phospho-Smad } 2 / 3 \\
\text { (Thr8) and Smad } 4 \text { in rat renal } \\
\text { tissues, and inhibition of the } \\
\text { TGF- } \beta / \text { Smad signaling pathway }\end{array}$ & {$[69,70]$} \\
\hline
\end{tabular}

exhibited renoprotective effects against streptozotocin-induced nephropathy in rats [50]. Likewise, in another study conducted by El-Soud et al., the renoprotective effect of C. carvi essential oil in streptozotocin-induced diabetic rats was examined. The results represented that the bioactive compounds of C. carvi exhibited renoprotection by increasing the activity of the antioxidant enzymes [51]. Moreover, Lahlou et al. demonstrated that the aqueous extract of C. carvi induced furosemide-like diuretic effects in rats [52]. 
TABLE 3: Examples of herbal plants with nephrotoxicity effects.

\begin{tabular}{|c|c|c|c|c|c|}
\hline Species & $\begin{array}{c}\text { English } \\
\text { name }\end{array}$ & Iranian name & Family & Risk & Reference \\
\hline Aloe ferox & Cape aloe & Sabr-e-zard & Asphodelaceae & Acute oliguric renal failure, interstitial nephritis, anuria & $\begin{array}{l}{[71]} \\
{[71]}\end{array}$ \\
\hline $\begin{array}{l}\text { Aristolochia } \\
\text { species }\end{array}$ & Birthwort & Zaravand & Aristolochiaceae & $\begin{array}{l}\text { Interstitial renal fibrosis, proximal tubular toxicity, } \\
\text { aristolochic acid nephropathy (AAN), severe hypocellular } \\
\text { interstitial fibrosis, urothelial dysplasia, renal failure with } \\
\text { interstitial fibrosis, Balkan endemic nephropathy (BEN), } \\
\text { Fanconi's syndrome }\end{array}$ & $\begin{array}{c}72] \\
{[73]} \\
{[74-76]} \\
{[77]} \\
{[78,79]} \\
{[73,80-82]} \\
\end{array}$ \\
\hline Ephedra sinica & Ephedra & $\begin{array}{l}\text { Houm or } \\
\text { rish-e-boz }\end{array}$ & Ephedraceae & $\begin{array}{l}\text { Hypertension, formation of kidney stones, nephritic colic, } \\
\text { rhabdomyolysis }\end{array}$ & $\begin{array}{l}{[83]} \\
{[84]} \\
{[84]} \\
{[85]}\end{array}$ \\
\hline $\begin{array}{l}\text { Glycyrrhiza } \\
\text { glabra }\end{array}$ & Liquorice & Shirin bayan & Fabaceae & $\begin{array}{l}\text { Renin-aldosterone system, Fanconi's tubulopathy, proximal } \\
\text { tubulopathy, hypokalemic rhabdomyolysis along with acute } \\
\text { renal failure }\end{array}$ & $\begin{array}{l}{[86]} \\
{[87]} \\
{[88]} \\
{[89]}\end{array}$ \\
\hline
\end{tabular}

TABLe 4: Fruit and vegetable sources of potassium, ranked by milligrams of potassium per standard amount*.

\begin{tabular}{|c|c|}
\hline Fruits and vegetables, standard amount & Potassium (mg) \\
\hline Sweet potato, baked, 1 potato $(146 \mathrm{~g})$ & 694 \\
\hline Tomato paste, $1 / 4$ cup & 664 \\
\hline Beet greens, cooked, $1 / 2$ cup & 655 \\
\hline Potato, baked, flesh, 1 potato $(156 \mathrm{~g})$ & 610 \\
\hline White beans, canned, $1 / 2$ cup & 595 \\
\hline Tomato puree, $1 / 2$ cup & 549 \\
\hline Prune juice, $3 / 4$ cup & 530 \\
\hline Carrot juice, $3 / 4$ cup & 517 \\
\hline Lima beans, cooked, $1 / 2$ cup & 484 \\
\hline Winter squash, cooked, $1 / 2$ cup & 448 \\
\hline Banana, 1 medium & 422 \\
\hline Spinach, cooked, $1 / 2$ cup & 419 \\
\hline Tomato juice, $3 / 4$ cup & 417 \\
\hline Tomato sauce, $1 / 2$ cup & 405 \\
\hline Peaches, dried, uncooked, $1 / 4$ cup & 398 \\
\hline Prunes, stewed, $1 / 2$ cup & 398 \\
\hline Apricots, dried, uncooked, $1 / 4$ cup & 378 \\
\hline Cantaloupe, $1 / 4$ medium & 368 \\
\hline Honeydew melon, $1 / 8$ medium & 365 \\
\hline Plantains, cooked, $1 / 2$ cup slices & 358 \\
\hline Kidney beans, cooked, $1 / 2$ cup & 358 \\
\hline Orange juice, $3 / 4$ cup & 355 \\
\hline Split peas, cooked, $1 / 2$ cup & 355 \\
\hline
\end{tabular}

* US Department of Health and Human Services and US Department of Agriculture, 2005. The dietary reference intake (DRI) for potassium for adults and adolescents is $4700 \mathrm{mg} /$ day.

3.1.3. Coriandrum sativum. C. sativum, known as geshniz in ITM, has been frequently used for the treatment of nephritis [32-34]. Lakhera et al. confirmed the nephroprotective role of the ethyl acetate extract of C. sativum in albino Wistar rats. It was illustrated that the extract significantly decreased creatinine levels, serum urea, and blood urea nitrogen. Furthermore, it improved renal histological lesions [53]. In another study, the renoprotective effect of combined administration of Cuminum cyminum and Coriandrum sativum in albino mice was proven by Kumar et al. [54]. Also, in a study conducted by El-Masry et al., C. sativum in combination with Foeniculum vulgare showed a significant improvement of serum creatinine and uric acid levels and boosted enzymatic and nonenzymatic antioxidants levels compared with the lead group [55]. Wu et al. proved that the ethanolic extracts of leaves and stems of $C$. sativum inhibited $\mathrm{NF}-\kappa \mathrm{B}$ activity and the mitogen-activated protein kinase (MAPK) signal transduction pathway in LPS-induced macrophages and had an anti-inflammatory effect [56].

3.1.4. Cucurbita pepo. C. pepo seeds, known as tokhmekadoo in ITM, have been broadly expended in Iran as a nephroprotective agent [33]. Adepoju and Adebanjo confirmed the nephroprotective activity of $C$. pepo seeds in albino rats [57].

3.1.5. Cydonia oblonga. C. oblonga, known as behi in ITM, is another plant used for the treatment of nephritis in Iran [32-34]. Mirmohammadlu et al. depicted that the aqueous extract of $C$. oblonga improved renal function in streptozotocin-induced diabetic rats. Accordingly, the extract decreased serum urea and creatinine levels [58]. Also, Aggarwal and Shishodia indicated the effect of caffeoylquinic acids obtained from C. oblonga on the reduction of NF- $\kappa \mathrm{B}$ and other inflammatory factors such as interferon gamma (IFN- $\gamma$ ), interleukin-2 (IL-2), extracellular signal-regulated kinases (ERK1/2), AKTa, nitric oxide (NO), and iNOS [59].

3.1.6. Ficus carica. The fruits of F. carica, known as anjir in ITM, have been recommended as a versatile remedy for nephritis [32, 33]. As reported by Kore et al., the hydroalcoholic extract of $F$. carica ameliorated gentamicin-induced nephrotoxicity in rats [60]. The extract enhanced catalase (CAT) and glutathione (GSH) concentrations and decreased the level of malondialdehyde (MDA) [60]. In a 
study conducted by Sharma et al., oral administration of morin derived from $F$. carica to male albino Wistar rats suppressed the NF- $\kappa$ B pathway and lessened inflammatory mediators such as TNF- $\alpha$, IL-6, COX-2, and prostaglandin (PGE-2) [61].

3.1.7. Linum usitatissimum. L. usitatissimum seeds, known as bazr-e-katan in ITM, have been extensively consumed to reduce kidney inflammation $[32,33]$. The nephroprotective effect of ground flaxseed in patients with lupus nephritis was assessed by Clark et al. [62]. In another study by Akpolat et al., the protective effect of seeds of $L$. usitatissimum on renal injury in rats was investigated. The results illustrated a decreased deposition of neutral lipid. Moreover, flaxseed alleviated renal injuries associated with hypercholesterolemia [63].

3.1.8. Melissa officinalis. Melissa officinalis L., known as badranjboya in ITM, has been frequently applied as a remedy for kidney inflammation $[33,96]$. Nephroprotective activity and anti-inflammatory effects of $M$. officinalis leaf extract against acetaminophen- and pleurisy-induced toxicity in rats were studied by Müzell et al. It was revealed that the aqueous extract possessed nephroprotective effects, leading to a decrease in the inflammation of kidney [64]. As reported by Hamza et al., oral administration of the ethanolic extract of $M$. officinalis leaves to male albino rats inhibited inflammatory responses to doxorubicin (DOX)induced inflammation by reducing the expressions of NF$\kappa \mathrm{B}, \mathrm{TNF}-\alpha$, and COX-2 [65].

3.1.9. Prunus amygdalus. P. amygdalus kernels, known as badam in ITM, have been frequently prescribed to improve the inflammation of kidney [32-34]. Renoprotective effects of hexane-isopropyl alcohol extract of almond kernels in streptozotocin-induced diabetic rats were reported by Demir et al. The extract reduced the MDA levels and GSH in the renal tissue [66]. Also, Pandey et al. proved the renal protective effect of ethanolic extract of $P$. amygdalus seeds in male Swiss albino rats. The results indicated that using the extract in a dose-dependent manner detracted the IL-6, IL-1b, TNF- $\alpha$, and inflammatory mediators PGE- 2 and NF- $\kappa$ B. Also, the renoprotective effect of $P$. amygdalus was observed in histopathological analyses [67]. Jamshed et al. showed that daily consumption of almond supplementation $(10 \mathrm{mg})$ before breakfast diminished serum uric acid in coronary artery disease patients [68].

3.1.10. Ziziphus jujuba Mill. Z. jujuba fruits, known as onab in ITM, have been used to treat nephritis [34]. Awad et al. investigated the renoprotective activity of the aqueous extract of $Z$. jujuba in rats by inducing nephrotoxicity with ibuprofen. The results demonstrated a significant decrease in serum urea and creatinine. This study suggested that taking ibuprofen with aqueous $Z$. jujuba extracts prevented the side effects of ibuprofen [69]. In the study reported by Zhao et al., the effect of injection of a patent herbal drug decoction prepared from 16 herbs including $Z$. jujuba, on the rat model of chronic glomerulonephritis, was evaluated. The results exhibited that the herbal drug decoction downregulated the proteins levels of transforming growth factor beta 1 (TGF$\beta 1$ ), phospho-small mothers against decapentaplegic (Smad) $2 / 3$ (Thr8), and Smad4 in rat renal tissues. It also inhibited the TGF- $\beta /$ Smad signaling pathway and improved all abnormal behavioral and biochemical changes in the model rats [70] (Table 2).

3.2. Plants with Adverse Renal Effects. Plants can cause side effects due to the presence of secondary metabolites and active compounds. Although they have shown beneficial effects in the treatment of kidney disease, some have demonstrated harmful effects [97]. The kidneys are susceptible to a wide variety of toxic insults due to high concentration of these compounds in the medullary interstitium and active uptake by tubular cells [83]. Adverse effects of herbal medicines on the kidneys can appear in different forms such as nephritis, hypertension, acute tubular necrosis, acute interstitial nephritis, Fanconi's syndrome, papillary necrosis, chronic interstitial renal fibrosis, urinary retention, kidney stones (nephrolithiasis, renal lithiasis), urinary tract carcinoma, hemorrhagic complications, and rhabdomyolysis [83]. Also, it can lead to food-drug interactions and changes in the potassium level $[98,99]$. Herein, some reported adverse effects have been listed in Table 3 .

\subsubsection{Plants with Nephrotoxicity Effects}

(1) Aloe ferox. The A. ferox leaves, known as Sabr-e-zard in ITM [96], contain aloesin (or aloeresin B) and aloeresin A [71] that have shown acute oliguric renal failure [71], interstitial nephritis, and anuria [71].

(2) Aristolochia species. Aristolochia species roots, known as zaravand in ITM [96], include aristolochic acid (AA) [74] that causes chronic interstitial renal fibrosis [72], proximal tubular toxicity [73], aristolochic acid nephropathy (AAN) $[74,75]$, severe hypocellular interstitial fibrosis, urothelial dysplasia [76], renal failure with interstitial fibrosis [77], Balkan endemic nephropathy (BEN) [78, 79], and Fanconi's syndrome [73, 80-82]. It seems that tubular compartment is the main target of AA and AA exerts apoptotic effects via activating mitochondrial permeability and activating caspase-3 [100]. Moreover, other mechanisms, including blocking out regeneration by changing epidermal growth factor (EGF) and vascular endothelial growth factor (VEGF) expression; increasing of epithelial-mesenchymal transition resulting in the accumulation of vimentin and $\alpha$-smooth muscle actin-positive cellsprobably via the influence of TGF$\beta$ and/or connective tissue growth factor (CTGF); and elevating the production of extracellular matrix components in the interstitium, have been reported in the literature [100-104]. Also, this compound is carcinogenic and uroepithelial cancers have been indicated in about $40-46 \%$ of patients who received total doses of AA higher than $200 \mathrm{~g}$ $[74,105,106]$. The carcinogenesis of AA is related to the strong affinity of AA metabolites for the exocyclic amino group of DNA and after binding to the adenine residues; these metabolites induce activation of Harvey rat sarcoma 
viral oncogene homolog (H-ras) and overexpression of tumor protein P53 (p53) [100, 107, 108].

(3) Ephedra sinica. The branches and fruits of E. sinica, known as houm or rish-e-boz in ITM [96], contain ephedrine [83] that can lead to hypertension [83], formation of kidney stones [84], nephritic colic [84], and rhabdomyolysis [85].

(4) Glycyrrhiza glabra. G. glabra. roots, known as shirin bayan in ITM [96], contain glycyrrhizic and glycyrrhetinic acids [109] that possess mineralocorticoid activity and can cause hypokalemia, sodium and water retention, metabolic alkalosis, hypertension, and suppression of the renin-aldosterone system [86]. Also, Fanconi's tubulopathy [87], proximal tubulopathy [88], and hypokalemic rhabdomyolysis along with acute renal failure [89] have been reported by the consumption of G. glabra.

3.2.2. Plants Interactions with Conventional Drugs. Some plants have metabolites that can provoke or inhibit the cytochrome P450 3A4 (P450 3A4) enzyme, which is the main enzyme involved in drug metabolism, and the drug transport protein P-glycoprotein 1 (p-gp) [2]. In this respect, they accelerate the clearance of drugs and diminish cyclosporine or tacrolimus bioavailability [2]. Also, these plants can raise the blood concentration of prednisolone [97]. Another interaction relates to the significant increase in the metabolism of immunosuppressive drugs, which causes the blood concentrations of those drugs to be reduced lower than the therapeutic levels, and the organ transplant recipients are prone to transplant rejection due to lower cyclosporine blood concentrations $[110,111]$.

One of the important plants that reduces the blood levels of cyclosporine is Hypericum perforatum that is known as St John's wort. One of the metabolites of St John's wort is hyperforin, which is a potent ligand for a nuclear receptor that regulates the expression of P450 3A4 monooxygenase $[91,93,112]$.

3.2.3. Plants Induce Changes in the Potassium Level. Some plants contain considerable amounts of potassium that may lead to hyperkalemia, chiefly in patients with kidney problems including chronic renal failure (Table 4) [83, 98]. Renal patients, who are particularly prone to hypokalemia and hyperkalemia, need dietary potassium restriction since intake of high potassium dietary levels can lead to the accumulation of potassium in patients with reduced kidney function and hyperkalemia [113, 114]. However, the drugs such as cyclosporine and tacrolimus induce hyperkalemia via inhibition of adrenal aldosterone biosynthesis [113]. Hyperkalemia can lead to metabolic acidosis and malignant arrhythmias as well as higher mortality [95].

Some potassium-rich plants such as alfalfa (Medicago sativa) and dandelion (Taraxacum officinale) can cause hyperkalemia particularly in the chronic renal failure patients. However, some plants, even with a low content of potassium, can lead to hyperkalemia, e.g., noni juice (Morinda officinalis) with potassium content of $56.3 \mathrm{mEq} / \mathrm{L}[83,115]$.

\section{Discussions}

Currently, immunosuppressive drugs are the most common drugs in the treatment of nephritis. However, incidence of different complications, in around $1 / 3$ of patients [25] using them, has led to the development of novel therapeutic strategies. In this respect, herbal remedies have attracted lots of attention due to their NF- $\kappa \mathrm{B}$ inhibitory potency through binding to peroxisome proliferator-activated receptor (PPAR) $\gamma[116,117]$. Considering the fact that NF- $\kappa \mathrm{B}$ is one of the most important proinflammatory cytokines causing nephritis, plant-based treatment can be a strong tool in the treatment of LN. ITM, which has focused on the properties of medicinal herbs, has provided useful remedies for LN. Most of these plants have been daily consumed for their culinary and medicinal goals for hundreds of years [118], and their therapeutic effects for the kidney disease and nephritis have been proven in various studies [119].

Among the plants recommended by ITM for the treatment of nephritis, some, including badranjboya (M. officinalis) [65], sheviid (A. graveolens) [49], geshniz (C. sativum) [56], behi (C. oblonga) [59], anjir (F. carica) [61], and badam (P. amygdalus) [67] have shown NF- $\kappa \mathrm{B}$ inhibitory activity. Moreover, many of these plants have also diminished other inflammatory factors such as iNOS, IL-6, TNF- $\alpha$, and COX-2 $[49,59,61,65]$.

Various studies have shown that vitamin deficiencies can cause LN and exacerbate inflammation in patients with SLE and kidney disease $[120,121]$. Plants that are rich in vitamin $A$, vitamin $E$, vitamin $D$, vitamin $C$, and vitamin $B 6$ have suppressed anti-dsDNA autoantibody production, Th17 cells, interleukin-17A (IL-17A)-producing $\mathrm{T}$ cells, lipid peroxidation, active inflammation, and IL- 6 secretion and increased Treg percentages in CD4+ T cells in patients with SLE $[28,122]$. Also, a number of studies have presented the favorable effects of these vitamins that decreased IL-2, IFN$\gamma$, and interleukin-12 (IL-12) and interleukin-4 (IL-4) in serum as well as immunoglobulin G2 (IgG2)-specific antiDNA antibody. They also increased TGF- $\beta$ and forkhead box P3 (FOXP3) mRNA expression and suppressed iNOS and monocyte chemoattractant protein-1 (MCP-1) in the kidney in the SLE models [28].

Plant food sources in addition to their role in providing dietary macronutrients and micronutrients are the major dietary sources of different plant secondary metabolites such as polyphenolic compounds including flavones, flavonols, flavan-3-ols, isoflavones, flavanones, and anthocyanidins, which play beneficial roles in human health [28, 123]. Different studies in patients with SLE and SLE models have revealed that plant secondary metabolites and polyphenolic compounds play an important role in the improvement of inflammatory processes in SLE leading to LN and renal complications, by suppressing IFN- $\gamma$ response and antidsDNA; reducing serum antinuclear antibodies and cytokines IL-17A, IL-1 $\beta$, TNF- $\alpha$, and IL-6; decreasing reactive oxygen species (ROS) levels in serum; decreasing serum 
creatinine and microalbumin; improving renal function, plasma lipids, blood viscosity; increasing complement C3 levels; decreasing proteinuria and splenic lymphocyte proliferation; and attenuating glomerular filtration and lymphoproliferation $[28,121,124]$.

Moreover, these plants including almond, flaxseed, pumpkin seeds, and caraway seeds are the source of n-6 polyunsaturated fatty acid (PUFA), n-3 PUFA, and monounsaturated fatty acid (MUFA) that have decreased fibronectin-1, intercellular adhesion molecule-1 (ICAM-1), TGF- $\beta 1 \mathrm{mRNA}$ levels and TGF- $\beta 1$ protein, IL- $1 \beta$, IL- 6 , and TNF- $\alpha$ in the kidney; increased antioxidant enzymes such as catalase, glutathione peroxidase (GPx), and superoxide dismutase (SOD) in the kidney; reduced the erythrocyte sedimentation rate and serum IL-12 levels, reduced platelet arachidonic acid, neutrophil leukotriene B4, and TAG; reduced the expressions of CD80, cytotoxic T-lymphocyteassociated protein 4 (CTLA-4), IL-10, C-C motif chemokine ligand 5 (CCL-5), C-X-C motif chemokine receptor 3 (CXCR3), and osteopontin mRNA in the kidney; downregulated NF- $\kappa$ B activation; decreased serum anti-dsDNA antibodies; ameliorated nuclear factor erythroid 2-related factor 2 (Nrf-2), heme oxygenase-1 (HO-1), JAK/STAT, $\mathrm{MAPK}$, and NF- $\kappa \mathrm{B}$ pathways in the kidney; and decreased serum matrix metalloproteinase-3 (MMP-3) and PGE-2 in the kidney in SLE models and patients with SLE $[28,121]$.

Although plants have depicted versatile effects on the treatment of inflammatory diseases such as lupus nephritis, they need an important attention as they may contain high levels of sodium, potassium, and phosphorus, leading to hypertension, fluid retention, hyperkalemia, and hyperphosphatemia. Hyperkalemia and hyperphosphatemia directly raise patient mortality in advanced CKD $[114,125,126]$. A low estimated glomerular filtration rate (eGFR) restricts renal potassium and phosphorus excretion in patients with CKD especially in ESRD, causing hyperkalemia and hyperphosphatemia $[114,126]$. Hypertension, fluid retention, hyperkalemia, and hyperphosphatemia can affect heart function, leading to acute myocardial ischemia, left ventricular hypertrophy, cardiac arrhythmia, congestive heart failure, and mortality $[114,125,127,128]$. So, the patients with low eGFR are recommended to restrict dietary potassium, phosphorus, and plant-based diets such as seeds, nuts, fruits, and vegetables $[125,128]$.

However, recent studies have demonstrated that the bioavailability of potassium and phosphorus in plant-based diets is less than meat-based diets due to high fiber content found in plant food, which may lead to steady serum potassium and phosphorus levels, correct metabolic acidosis, delay advancement to dialysis and ESRD, and mitigate mortality [128, 129]. Furthermore, it has been revealed that restriction in alimentary potassium and phosphorus intake resulted in unplanned diminutions in beneficial macronutrients especially reducing protein, which is associated with the occurrence of malnutrition in patients' kidney. On the other hand, it was shown that potassium- and phosphorus-limiting diets have little effect on maintaining normal serum potassium and phosphorus levels [128-131]. The use of plant-based diets in CKD may have other advantages including decrease in weight, hypertension, hyperphosphatemia, hyperfiltration, and possibly mortality [132]. Furthermore, plant-based diets are beneficial as long as the diet is properly implemented to provide adequate protein intake, including essential amino acids [132].

Goldner studied the effect of raw, whole-food, plantbased (WfPB) diets on two patients with SLE-related nephritis. The results illustrated that in Case 1, the eGFR enhanced from 14 to $27 \mathrm{ml} / \mathrm{min}$ in 6 weeks and did not need dialysis or a kidney transplant. In Case 2, laboratory tests were normalized and symptoms were improved due to dietary changes to WfPB diets [133].

It should be noted that some plants such as G. glabra, Aristolochia species, A. ferox, and E. sinica have demonstrated nephrotoxicity effects and need the attention of patients who are affected by nephritis and kidney inflammation. Therefore, nutritional interventions in the renal patients should be considered for the possible renal toxicity provided by plants $[2,83]$.

\section{Conclusion}

ITM has provided a plant-based approach to nephritis to preserve or recover renal function. These plants have depicted anti-inflammatory effects via different pathways and are prone to be developed as dietary supplements.

\section{Abbreviations}

$\begin{array}{ll}\text { LN: } & \text { Lupus nephritis } \\ \text { ITM: } & \text { Iranian traditional medicine } \\ \text { VK: } & \text { Varam-e-Kolye } \\ \text { SLE: } & \text { Systemic lupus erythematosus } \\ \text { NF- } \kappa \text { B: } & \text { Nuclear factor kappa B } \\ \text { COX-2: } & \text { Cyclooxygenase-2 } \\ \text { Th1: } & \text { T helper 1 } \\ \text { Th17: } & \text { T helper 17 } \\ \text { Anti-dsDNA: } & \text { Anti-double-stranded DNA } \\ \text { IL-6: } & \text { Interleukin-6 } \\ \text { IL-17: } & \text { Interleukin-17 } \\ \text { IL-23: } & \text { Interleukin-23 } \\ \text { TNF- } \alpha: & \text { Tumor necrosis factor- } \alpha \\ \text { Tregs: } & \text { T regulator cells } \\ \text { ESRD: } & \text { End-stage renal disease } \\ \text { CD20: } & \text { B-lymphocyte antigen CD20 } \\ \text { ISN/RPS: } & \text { International Society of Nephrology/Renal } \\ & \text { Pathology Society } \\ \text { RAAS: } & \text { Renin-angiotensin-aldosterone system } \\ \text { ACR: } & \text { American College of Rheumatology } \\ \text { EULAR/ERA- } & \text { European League Against Rheumatism and } \\ \text { EDTA: } & \text { European Renal Association-European } \\ \text { iNOS: } & \text { Dialysis and Transplant Association } \\ \text { Akt: } & \text { Inducible nitric oxide synthase } \\ \text { LPS: } & \text { Serine/threonine kinase 1 } \\ \text { MAPK: } & \text { Lipopolysaccharide } \\ \text { IFN-g: } & \text { Mitogen-activated protein kinase } \\ \text { IL-2: } & \text { Interferon gamma } \\ \text { ERK1/2: } & \text { Exterleukin-2 } \\ \text { CAT: } & \text { Catalase } \\ & \end{array}$




\begin{tabular}{|c|c|}
\hline GSH: & Glutathione \\
\hline MDA: & Malondialdehyde \\
\hline PGE-2: & Prostaglandin E-2 \\
\hline DOX: & Doxorubicin \\
\hline Smad: & Small mothers against decapentaplegic \\
\hline TGF- $\beta 1:$ & Transforming growth factor beta 1 \\
\hline AA: & Aristolochic acid \\
\hline AAN: & Aristolochic acid nephropathy \\
\hline EGF: & Epidermal growth factor \\
\hline VEGF: & Vascular endothelial growth factor \\
\hline CTGF: & Connective tissue growth factor \\
\hline H-ras: & $\begin{array}{l}\text { Harvey rat sarcoma viral oncogene } \\
\text { homolog }\end{array}$ \\
\hline p53: & Tumor protein p53 \\
\hline P450 3A4: & Cytochrome P450 3A4 \\
\hline p-gp: & P-glycoprotein 1 \\
\hline PPAR: & Peroxisome proliferator-activated receptor \\
\hline IL-17A: & Interleukin-17A \\
\hline IL-12: & Interleukin-12 \\
\hline IL-4: & Interleukin-4 \\
\hline IgG2: & Immunoglobulin G2 \\
\hline FOXP3: & Forkhead box P3 \\
\hline MCP-1: & Monocyte chemoattractant protein-1 \\
\hline ROS: & Reactive oxygen species \\
\hline PUFA: & Polyunsaturated fatty acid \\
\hline MUFA: & Monounsaturated fatty acid \\
\hline ICAM-1: & Intercellular adhesion molecule-1 \\
\hline GPx: & Glutathione peroxidase \\
\hline SOD: & Superoxide dismutase \\
\hline CTLA-4: & $\begin{array}{l}\text { Cytotoxic T-lymphocyte-associated } \\
\text { protein } 4\end{array}$ \\
\hline CCL-5: & C-C motif chemokine ligand 5 \\
\hline CXCR3: & C-X-C motif chemokine receptor 3 \\
\hline Nrf-2: & Nuclear factor erythroid 2-related factor 2 \\
\hline HO-1: & Heme oxygenase- 1 \\
\hline MMP-3: & Matrix metalloproteinase-3 \\
\hline eGFR: & Estimated glomerular filtration rate \\
\hline WfPB: & Raw, whole-food, plant-based. \\
\hline
\end{tabular}

\section{Data Availability}

The data supporting this review are from the previously reported studies and datasets, which have been cited. The data used to support the findings of this study are available from the corresponding author upon request.

\section{Conflicts of Interest}

The authors declare that there are no conflicts of interest.

\section{Authors' Contributions}

Yasaman Vahedi-Mazdabadi carried out the conceptualization, methodology, investigation of the study, wrote the original draft, and reviewed and edited the manuscript. Mina Saeedi carried out the supervision and methodology of the study and reviewed and edited the manuscript. All authors reviewed the final manuscript.

\section{Acknowledgments}

The authors thank the support from Tehran University of Medical Sciences.

\section{References}

[1] I. M. Bajema, S. Wilhelmus, C. E. Alpers et al., "Revision of the International Society of nephrology/renal pathology society classification for lupus nephritis: clarification of definitions, and modified national institutes of health activity and chronicity indices," Kidney International, vol. 93, no. 4, pp. 789-796, 2018.

[2] A. C. Brown, "Kidney toxicity related to herbs and dietary supplements: online table of case reports. Part 3 of 5 series," Food and Chemical Toxicology, vol. 107, pp. 502-519, 2017.

[3] L. Zhang, J. Wang, C.-W. Yang et al., "International Society of Nephrology Global Kidney Health Atlas: structures, organization and services for the management of kidney failure in North and East Asia," Kidney International Supplements, vol. 11, no. 2, pp. e77-e85, 2021.

[4] J. K.-C. Ng and P. K.-T. Li, "Chronic kidney disease epidemic: how do we deal with it?" Nephrology, vol. 23, pp. 116-120, 2018.

[5] S. Almaani, A. Meara, and B. H. Rovin, "Update on lupus nephritis," Clinical Journal of the American Society of $\mathrm{Ne}$ phrology, vol. 12, no. 5, pp. 825-835, 2017.

[6] R. Balasubramanian and S. D. Marks, "Post-infectious glomerulonephritis," Paediatrics and International Child Health, vol. 37, no. 4, pp. 240-247, 2017.

[7] R. Rong, Q. Wen, and Y. Wang, "Prognostic significance of hypertension at the onset of lupus nephritis in Chinese patients: prevalence and clinical outcomes," Journal of Human Hypertension, pp. 1-10, 2021.

[8] K. Trotter, M. R. Clark, and V. M. Liarski, "Overview of pathophysiology and treatment of human lupus nephritis," Current Opinion in Rheumatology, vol. 28, no. 5, pp. 460467, 2016.

[9] S. A. M. E. G. Timmermans, M. H. L. Christiaans, M. A. Abdul-Hamid, F. Stifft, J. G. M. C. Damoiseaux, and P. van Paassen, "Granulomatous interstitial nephritis and Crohn's disease," Clinical Kidney Journal, vol. 9, no. 4, pp. 556-559, 2016.

[10] S. Oyama, K. Hosohata, A. Inada et al., "Drug-induced tubulointerstitial nephritis in a retrospective study using spontaneous reporting system database," Therapeutics and Clinical Risk Management, vol. 14, p. 1599, 2018.

[11] Q. Hu, C. Yang, Q. Wang, H. Zeng, and W. Qin, "Demethylzeylasteral (T-96) treatment ameliorates mice lupus nephritis accompanied by inhibiting activation of NF- $\kappa \mathrm{B}$ pathway," PLoS One, vol. 10, no. 7, Article ID e0133724, 2015.

[12] E. Habas and F. Y. Khan, "Lupus nephritis; pathogenesis and treatment update review," Open Science Journal, vol. 6, no. 1, 2021.

[13] S. A. Chalmers, S. J. Garcia, J. A. Reynolds, L. Herlitz, and C. Putterman, "NF-kB signaling in myeloid cells mediates the pathogenesis of immune-mediated nephritis," Journal of Autoimmunity, vol. 98, pp. 33-43, 2019.

[14] M. dos Santos, P. T. Poletti, G. Favero et al., "Protective effects of quercetin treatment in a pristane-induced mouse model of lupus nephritis," Autoimmunity, vol. 51, no. 2, pp. 69-80, 2018.

[15] N. Z. Saber, S. H. Maroof, D. A. Soliman, and M. S. Fathi, "Expression of T helper 17 cells and interleukin 17 in lupus 
nephritis patients," The Egyptian Rheumatologist, vol. 39, no. 3, pp. 151-157, 2017.

[16] D. Mesquita, G. M. Kirsztajn, M. F. Franco et al., "CD4+ T helper cells and regulatory T cells in active lupus nephritis: an imbalance towards a predominant Th1 response?" Clinical and Experimental Immunology, vol. 191, no. 1, pp. 50-59, 2018.

[17] Q. Liu, Y. Du, and K. Li, "Anti-OSM antibody inhibits tubulointerstitial lesion in a murine model of lupus nephritis," Mediators of Inflammation, vol. 2017, Article ID 3038514, 7 pages, 2017.

[18] H. J. Anders, R. Saxena, M. H. Zhao, I. Parodis, J. E. Salmon, and C. Mohan, "Lupus nephritis," Nature Reviews. Disease Primers, vol. 6, no. 1, pp. 7-25, 2020.

[19] A. Farid, T. Abd Almolaa, and G. Safwat, "Complements as a predictive biomarker of lupus nephritis in female patients with systemic lupus erythematosus," International Journal of Clinical Biochemistry and Research, vol. 4, no. 3, pp. 201-207, 2020.

[20] I. Parodis, H. Ding, A. Zickert et al., "Serum soluble tumour necrosis factor receptor-2 (sTNFR2) as a biomarker of kidney tissue damage and long-term renal outcome in lupus nephritis," Scandinavian Journal of Rheumatology, vol. 46, no. 4, pp. 263-272, 2017.

[21] H.-Y. Yang, C.-Y. Wu, F. Pan, D. Pardoll, and C.-W. Yang, "Micromanaging lupus nephritis: miR17-92 modulates TFH development and regulatory T cell activity," American Association of Immunologists, vol. 198, 2017.

[22] L. Bao, P. N. Cunningham, and R. J. Quigg, "Complement in lupus nephritis: new perspectives," Kidney Disease, vol. 1, no. 2, pp. 91-99, 2015.

[23] S. Al Sawah, X. Zhang, and B. Zhu, "Effect of corticosteroid use by dose on the risk of developing organ damage over time in systemic lupus erythematosus-the Hopkins Lupus Cohort," Lupus Science and Medicine, vol. 2, no. 1, Article ID e000066, 2015.

[24] A. Legge, S. Doucette, and J. G. Hanly, "Predictors of organ damage progression and effect on health-related quality of life in systemic lupus erythematosus," Journal of Rheumatology, vol. 43, no. 6, pp. 1050-1056, 2016.

[25] G. Moroni, F. Raffiotta, and C. Ponticelli, "Remission and withdrawal of therapy in lupus nephritis," Journal of $\mathrm{Ne}$ phrology, vol. 29, no. 4, pp. 559-565, 2016.

[26] M. Kostopoulou, C. Adamichou, and G. Bertsias, "An update on the diagnosis and management of lupus nephritis," Current Rheumatology Reports, vol. 22, no. 7, p. 30, 2020.

[27] B. Marakkath and C. Mohan, "Can a plant-derived compound provide a lupus lifeline?" International Journal of Clinical Rheumatology, vol. 10, no. 2, pp. 57-60, 2015.

[28] M. Aparicio-Soto, M. Sánchez-Hidalgo, and C. Alarcón-dela-Lastra, "An update on diet and nutritional factors in systemic lupus erythematosus management," Nutrition Research Reviews, vol. 30, no. 1, pp. 118-137, 2017.

[29] W. Wijesinghe, S. Pilapitiya, P. Hettiarchchi, B. Wijerathne, and S. Siribaddana, "Regulation of herbal medicine use based on speculation? a case from Sri Lanka," Journal of Traditional and Complementary Medicine, vol. 7, no. 2, pp. 269-271, 2017.

[30] W.-H. Tsai, C.-C. Yang, P.-C. Li, W.-C. Chen, and C.-T. Chien, "Therapeutic potential of traditional Chinese medicine on inflammatory diseases," Journal of Traditional and Complementary Medicine, vol. 3, no. 3, pp. 142-151, 2013.
[31] M. Mahjour, A. Khoushabi, M. M. G. Novi, and Z. Feyzabadi, "Food strategies of renal atrophy based on Avicenna and conventional medicine," Journal of Traditional and Complementary Medicine, vol. 7, 2017.

[32] I. Sina, "The canon of medicine (Sharafkandi A, trans), (in Persian) Tehran," 2010.

[33] M. Arzani, "Tibb al-akbar (Akbar's Medicine) (in Persian)," Research Institute for Islamic and Complementary Medicine (RICM), vol. 2, 2008.

[34] H. Nazem Jahan, "Exire-azam (in Persian)," Research Institute for Islamic and Complementary Medicine Tehran, vol. 3, 2008.

[35] A. M. Uber and S. M. Sutherland, "Nephrotoxins and nephrotoxic acute kidney injury," Pediatric Nephrology, vol. 35, no. 10, pp. 1825-1833, 2020.

[36] F. Holden, V. Amin, D. Kuek, J. B. Kopp, B. M. Hendry, and Q.-H. Xu, "“Taming the fire of nephrotoxic botanicals," World Journal of Traditional Chinese Medicine, vol. 5, no. 3, p. 151, 2019.

[37] B. Yang, Y. Xie, M. Guo, M. H. Rosner, H. Yang, and C. Ronco, "Nephrotoxicity and Chinese Herbal Medicine," Clinical Journal of the American Society of Nephrology, vol. 13, no. 10, pp. 1605-1611, 2018.

[38] N. Maroz and M. S. Segal, "Lupus Nephritis and End-stage Kidney Disease," The American Journal of the Medical Sciences, vol. 346, no. 4, pp. 319-323, 2013.

[39] H.-J. Anders and B. Rovin, "A pathophysiology-based approach to the diagnosis and treatment of lupus nephritis," Kidney International, vol. 90, no. 3, pp. 493-501, 2016.

[40] J. J. Weening, V. D. D'agati, V. D. D'agati et al., “The classification of glomerulonephritis in systemic lupus erythematosus revisited," Kidney International, vol. 65, no. 2, pp. 521-530, 2004.

[41] K. Uchida and K. Nitta, "Recent advances in the treatment of lupus nephritis," Clinical and Experimental Nephrology, vol. 16, no. 2, pp. 202-213, 2012

[42] A. Davidson and C. Aranow, "Pathogenesis and treatment of systemic lupus erythematosus nephritis," Current Opinion in Rheumatology, vol. 18, no. 5, pp. 468-475, 2006.

[43] F. Houssiau and E. Ginzler, "Current treatment of lupus nephritis," Lupus, vol. 17, no. 5, pp. 426-430, 2008.

[44] M. L. Ishimori, V. Gudsoorkar, S. R. Venuturupalli, and M. H. Weisman, "Disparities in renal replacement in lupus nephritis: Current practice and future implications," Arthritis Care and Research, vol. 63, no. 12, pp. 1639-1641, 2011.

[45] A. J. Sabucedo and G. Contreras, "ESKD, transplantation, and dialysis in lupus nephritis," Seminars in Nephrology, vol. 35, no. 5, pp. 500-508, 2015.

[46] K. Karasawa, K. Uchida, T. Takabe, T. Moriyama, and K. Nitta, "Recent advances in treatment strategies for lupus nephritis," Contributions to Nephrology, vol. 195, pp. 42-50, 2018.

[47] S. Wilhelmus, I. M. Bajema, G. K. Bertsias et al., "Lupus nephritis management guidelines compared," Nephrology Dialysis Transplantation, vol. 31, no. 6, pp. 904-913, 2015.

[48] L. W. Khalil and W. A. Shakir, "The protective role of alcoholic extract of (Anethum graveolens) seeds on renal function in alloxan induced diabetic rabbits," Iraqi Journal of Veterinary Medicine, vol. 39, no. 2, pp. 1-6, 2015.

[49] Y.-J. Kim, Y. Shin, K. H. Lee, and T.-J. Kim, "Anethum graveloens Flower Extracts Inhibited a LipopolysaccharideInduced Inflammatory Response by Blocking iNOS Expression and NF- $\kappa \mathrm{B}$ Activity in Macrophages," Bioscience 
Biotechnology and Biochemistry, vol. 76, no. 6, pp. 11221127, 2012.

[50] S. Sadiq, A. H. Nagi, M. Shahzad, and A. Zia, "The renoprotective effect of aqueous extract of Carum carvi (black zeera) seeds in streptozotocin induced diabetic nephropathy in rodents," Saudi Journal of Kidney Diseases and Transplantation, vol. 21, no. 6, p. 1058, 2010.

[51] N. H. A. El-Soud, N. A. El-Lithy, and G. El-Saeed, "Renoprotective effects of caraway (Carum carvi L.) essential oil in streptozotocin induced diabetic rats," Journal of Applied Pharmaceutical Science, vol. 4, no. 2, p. 27, 2014.

[52] S. Lahlou, A. Tahraoui, Z. Israili, and B. Lyoussi, "Diuretic activity of the aqueous extracts of Carum carvi and Tanacetum vulgare in normal rats," Journal of Ethnopharmacology, vol. 110, no. 3, pp. 458-463, 2007.

[53] A. Lakhera, A. Ganeshpurkar, D. Bansal, and N. Dubey, "Chemopreventive role of Coriandrum sativum against gentamicin-induced renal histopathological damage in rats," Interdisciplinary Toxicology, vol. 8, no. 2, pp. 99-102, 2015.

[54] A. Kumar, J. K. Singh, and M. Ali, "“Evaluation of Cuminum cyminum and Coriandrum sativum on Profenofos induced nephrotoxicity in Swiss albino mice," Elixir Applied Botany, vol. 39, pp. 4771-4774, 2011.

[55] S. El-Masry, H. Ali, N. M. El-Sheikh, and S. M. Awad, "Dosedependent effect of coriander (CoriandrumSativum L.) and fennel (FoeniculumVulgare M.) on lead nephrotoxicity in rats," International Journal of Research Studies in Biosciences, vol. 4, no. 6, pp. 36-45, 2016.

[56] T.-T. Wu, C.-W. Tsai, H.-T. Yao et al., "Suppressive effects of extracts from the aerial part of Coriandrum sativum L. on LPS-induced inflammatory responses in murine RAW 264.7 macrophages," Journal of the Science of Food and Agriculture, vol. 90, no. 11, pp. 1846-1854, 2010.

[57] A. Adepoju and A. Adebanjo, "Effect of consumption of Cucurbita pepo seeds on haematological and biochemical parameters," African Journal of Pharmacy and Pharmacology, vol. 5, no. 1, pp. 18-22, 2009.

[58] M. Mirmohammadlu, S. H. Hosseini, M. Kamalinejad, M. Esmaeili Gavgani, M. Noubarani, and M. R. Eskandari, "Hypolipidemic, hepatoprotective and renoprotective effects of Cydonia oblonga Mill. Fruit in streptozotocin-induced diabetic rats," Iranian Journal of Pharmaceutical Research : Iranian Journal of Pharmaceutical Research, vol. 14, no. 4, pp. 1207-14, 2015.

[59] B. B. Aggarwal and S. Shishodia, "Molecular targets of dietary agents for prevention and therapy of cancer," Biochemical Pharmacology, vol. 71, no. 10, pp. 1397-1421, 2006.

[60] K. J. Kore, R. V. Shete, B. N. Kale, and A. S. Borade, "Protective role of hydroalcoholic extract of Ficus carica in gentamicin induced nephrotoxicity in rats," International Journal of Pharmacy and Life Sciences, vol. 2, no. 8, 2011.

[61] S. H. Sharma, J. S. Kumar, D. R. Chellappan, and S. Nagarajan, "Molecular chemoprevention by morin-a plant flavonoid that targets nuclear factor kappa B in experimental colon cancer," Biomedicine and Pharmacotherapy, vol. 100, pp. 367-373, 2018.

[62] W. F. Clark, C. Kortas, A. P. Heidenheim, J. Garland, E. Spanner, and A. Parbtani, "Flaxseed in lupus nephritis: a two-year nonplacebo-controlled crossover study," Journal of the American College of Nutrition, vol. 20, no. 2, pp. 143-148, 2001.

[63] M. Akpolat, M. Kanter, Y. Topcu-Tarladacalisir, and N. Aydogdu, "Protective Effect of flaxseed oil on renal injury in hyperlipidaemic rats: the effect of flaxseed oil on hyperlipidaemia," Phytotherapy Research, vol. 25, no. 6, pp. 796-802, 2011.

[64] D. P. Müzell, A. Lunardelli, C. E. Leite et al., "Nephroprotective and anti-inflammatory effects of aqueous extract of Melissa officinalis L. on acetaminophen-induced and pleurisy-induced lesions in rats," Brazilian Archives of Biology and Technology, vol. 56, no. 3, pp. 383-392, 2013.

[65] A. A. Hamza, M. M. Ahmed, H. M. Elwey, and A. Amin, "Melissa officinalis protects against doxorubicin-induced cardiotoxicity in rats and potentiates its anticancer activity on MCF-7 Cells," PLoS One, vol. 11, no. 11, Article ID e0167049, 2016.

[66] E. Demir, S. Keser and Ö. Yilmaz, Protective effects of bitter almond kernel extract on liver and kidney tissues in streptozotocin-induced diabetic rats," Turkish Journal of Science and Technology, vol. 10, no. 1, 2015.

[67] P. Pandey, P. C. Bhatt, M. Rahman et al., "Preclinical renal chemo-protective potential of Prunus amygdalus Batsch seed coat via alteration of multiple molecular pathways," Archives of Physiology and Biochemistry, vol. 124, no. 1, pp. 88-96, 2018.

[68] H. Jamshed, A.-U.-H. Gilani, F. A. T. Sultan et al., "Almond supplementation reduces serum uric acid in coronary artery disease patients: a randomized controlled trial," Nutrition Journal, vol. 15, no. 1, p. 77, 2015.

[69] D. S. Awad, R. M. Ali, N. M. Mhaidat, and A. M. Shotar, "Zizyphus jujubaprotects against ibuprofen-induced nephrotoxicity in rats," Pharmaceutical Biology, vol. 52, no. 2, pp. 182-186, 2014.

[70] J. Zhao, Y.-C. Chan, B. He, T.-T. Duan, and Z.-L. Yu, “A patent herbal drug Yi-Shen-Hua-Shi granule ameliorates C-BSA-induced chronic glomerulonephritis and inhabits TGF $\beta$ signaling in rats," Journal of Ethnopharmacology, vol. 236, pp. 258-262, 2019.

[71] V. A. Luyckx, R. Ballantine, M. Claeys et al., "Herbal remedyassociated acute renal failure secondary to Cape aloes," American Journal of Kidney Diseases, vol. 39, no. 3, pp. e13. 11-e13. 15, 2002.

[72] G. Du, S. Zhou, and Y. Zhao, “"Experimental study of chronic renal tubular-interstitial injury induced by radix Aristolochiae fangchi extract in rats," China Journal of Chinese Materia Medica, vol. 30, no. 8, pp. 610-613, 2005.

[73] Y. Yu, F. Zheng, and H. Li, "Chinese herbs-induced renal failure with Fanconi syndrome: a report of 6 cases," Zhonghua Nei Ke Za Zhi, vol. 42, no. 2, pp. 110-112, 2003.

[74] J.-P. Cosyns, "Aristolochic acid and 'Chinese herbs nephropathy',” Drug Safety, vol. 26, no. 1, pp. 33-48, 2003.

[75] M. R. Ardalan, L. Khodaie, H. Nasri, and A. Jouyban, "Herbs and hazards: risk of aristolochic acid nephropathy in Iran," Iranian Journal of Kidney Diseases, vol. 9, no. 1, pp. 14-7, 2015.

[76] J.-P. Cosyns, J.-P. Dehoux, Y. Guiot et al., "Chronic aristolochic acid toxicity in rabbits: a model of Chinese herbs nephropathy?" Kidney International, vol. 59, no. 6, pp. 2164-2173, 2001.

[77] F. D. Debelle, J. L. Nortier, E. G. De Prez et al., “Aristolochic Acids Induce Chronic Renal Failure with Interstitial Fibrosis in Salt-Depleted Rats," Journal of the American Society of Nephrology, vol. 13, no. 2, pp. 431-436, 2002.

[78] M. E. De Broe, "Chinese herbs nephropathy and Balkan endemic nephropathy: toward a single entity, aristolochic acid nephropathy," Kidney International, vol. 81, no. 6, pp. 513-515, 2012. 
[79] F. D. Debelle, J.-L. Vanherweghem, and J. L. Nortier, "Aristolochic acid nephropathy: a worldwide problem," Kidney International, vol. 74, no. 2, pp. 158-169, 2008.

[80] A. Tanaka, R. Nishida, H. Yokoi, and T. Kuwahara, “"The characteristic pattern of aminoaciduria in patients with aristolochic acid-induced Fanconi syndrome: could iminoaciduria be the hallmark of this syndrome?" Clinical Nephrology, vol. 54, no. 3, pp. 198-202, 2000.

[81] B. Krumme, R. Endmeir, M. Vanhaelen, and D. Walb, "Reversible Fanconi syndrome after ingestion of a Chinese herbal 'remedy' containing aristolochic acid," Nephrology Dialysis Transplantation, vol. 16, no. 2, pp. 400-402, 2001.

[82] A. Tanaka, R. Nishida, K. . a. Maeda, A. Sugawara, and T. Kuwahara, "Chinese herb nephropathy in Japan presents adult-onset Fanconi syndrome: could different components of aristolochic acids cause a different type of Chinese herb nephropathy?" Clinical Nephrology, vol. 53, no. 4, pp. 301306, 2000.

[83] C. Isnard Bagnis, G. Deray, A. Baumelou, M. Le Quintrec, and J. L. Vanherweghem, "Herbs and the kidney," American Journal of Kidney Diseases, vol. 44, no. 1, pp. 1-11, 2004.

[84] T. Powell, F. Hsu, J. Turk, and K. Hruska, "Ma-huang strikes again: ephedrine nephrolithiasis," American Journal of Kidney Diseases, vol. 32, no. 1, pp. 153-159, 1998.

[85] C. E. Stahl, C. V. Borlongan, M. Szerlip, and H. Szerlip, "No pain, no gain--exercise-induced rhabdomyolysis associated with the performance enhancer herbal supplement ephedra," Medical Science Monitor, vol. 12, no. 9, pp. CS81-4, 2006.

[86] P. Stewart, R. Valentino, A. M. Wallace, D. Burt, C. L. Shackleton, and C. W. Edwards, "Mineralocorticoid activity of liquorice: 11-beta-hydroxysteroid dehydrogenase deficiency comes of age," The Lancet, vol. 330, no. 8563, pp. 821-824, 1987.

[87] T. Izumotani, E. Ishimura, K. Tsumura, K. Goto, Y. Nishizawa, and H. Morii, "An adult case of Fanconi syndrome due to a mixture of Chinese crude drugs," Nephron, vol. 65, no. 1, pp. 137-140, 1993.

[88] C. Delcroix, E. Poncin, O. Pourrat, P. Thomas, and J. Allal, "Proximal tubulopathy in licorice poisoning," Presse Medicale (Paris, France: 1983), vol. 14, no. 46, pp. 2346-2347, 1985.

[89] T. Saito, Y. Tsuboi, G. Fujisawa et al., "An autopsy case of licorice-induced hypokalemic rhabdomyolysis associated with acute renal failure: special reference to profound calcium deposition in skeletal and cardiac muscle," Nihon Jinzo Gakkai Shi, vol. 36, no. 11, pp. 1308-1314, 1994.

[90] R. W. Byard, "A Review of the Potential Forensic Significance of Traditional Herbal Medicines," Journal of Forensic Sciences, vol. 55, no. 1, pp. 89-92, 2010.

[91] C. Moschella and B. L. Jaber, "Interaction between cyclosporine and Hypericum perforatum (St. John's wort) after organ transplantation," American Journal of Kidney Diseases, vol. 38, no. 5, pp. 1105-1107, 2001.

[92] S. Bauer, E. Störmer, A. Johne et al., "Alterations in cyclosporin A pharmacokinetics and metabolism during treatment with St John's wort in renal transplant patients," British Journal of Clinical Pharmacology, vol. 55, no. 2, pp. 203-211, 2003.

[93] A. Fugh-Berman, "Herb-drug interactions," The Lancet, vol. 355 , no. 9198 , pp. 134-138, 2000.

[94] B. F. Palmer and D. J. Clegg, "Physiology and pathophysiology of potassium homeostasis," Advances in Physiology Education, vol. 40, no. 4, pp. 480-490, 2016.
[95] L. Fried, C. P. Kovesdy, and B. F. Palmer, "New options for the management of chronic hyperkalemia," Kidney International Supplements, vol. 7, no. 3, pp. 164-170, 2017.

[96] M. Aghili, Makhzan-al-Advia, Tehran University of Medical Sciences, Tehran, Iran, 2009.

[97] K. Wojcikowski, D. W. Johnson, and G. Gobe, "Review Article. Medicinal herbal extracts - renal friend or foe? Part one: the toxicities of medicinal herbs," Nephrology, vol. 9, no. 5, pp. 313-318, 2004.

[98] J. Foote and B. Cohen, "Medicinal herb use and the renal patient," Journal of Renal Nutrition, vol. 8, no. 1, pp. 40-42, 1998.

[99] R. Bolley, C. Zülke, M. Kammerl, M. Fischereder, and B. K. Krämer, "Tacrolimus-induced nephrotoxicity unmasked by induction of the CYP3A4 system with ST John's wort," Transplantation, vol. 73, no. 6, p. 1009, 2002.

[100] V. Jha, "Herbal medicines and chronic kidney disease," Nephrology, vol. 15, pp. 10-17, 2010.

[101] R. Gao, F. Zheng, Y. Liu et al., “Aristolochic acid I-induced apoptosis in LLC-PK1 cells and amelioration of the apoptotic damage by calcium antagonist," Chinese Medical Journal, vol. 113, no. 5, pp. 418-424, 2000.

[102] B. Li, X. Li, C. Zhang, X. Wang, and S. Cai, "Injury in renal proximal tubular epithelial cells induced by aristololactam I," China Journal of Chinese Materia Medica, vol. 29, no. 1, pp. 78-83, 2004.

[103] Y.-J. Wen, T. Su, J.-W. Tang et al., "Cytotoxicity of phenanthrenes extracted from Aristolochia contorta in human proximal tubular epithelial cell line," Nephron Experimental Nephrology, vol. 103, no. 3, pp. e95-e102, 2006.

[104] L. Yang, X. Li, and H. Wang, "“A comparative study of manchurian Dutchmanspipe and antibiotics induced acute tubular necrosis in renal cellular biological features," Chinese Journal of Integrated Traditional and Western Medicine, vol. 23, no. 5, pp. 329-334, 2003.

[105] J. L. Nortier, M.-C. M. Martinez, H. H. Schmeiser et al., "Urothelial Carcinoma Associated with the Use of a Chinese Herb (Aristolochia fangchi)," New England Journal of Medicine, vol. 342, no. 23, pp. 1686-1692, 2000.

[106] J. L. Nortier and J. L. Vanherweghem, "Renal interstitial fibrosis and urothelial carcinoma associated with the use of a Chinese herb (Aristolochia fangchi)," Toxicology, vol. 181, pp. 577-580, 2002.

[107] R. Fernando, H. Schmeiser, H. Scherf, and M. Wiessler, "Formation and persistence of specific purine DNA adducts by $32 \mathrm{P}$-postlabelling in target and non-target organs of rats treated with aristolochic acid I," IARC Scientific Publications, vol. 124, pp. 167-171, 1993.

[108] G. M. Lord, M. Hollstein, V. M. Arlt et al., "DNA adducts and p53 mutations in a patient with aristolochic acid-associated nephropathy," American Journal of Kidney Diseases, vol. 43, no. 4, pp. e18. 11-e18. 17, 2004.

[109] B. Tomlinson, T. Y. K. Chan, J. C. N. Chan, J. A. J. H. Critchley, and P. P. H. But, "Toxicity of complementary therapies: an eastern perspective," The Journal of Clinical Pharmacology, vol. 40, no. 5, pp. 451-456, 2000.

[110] G. W. Barone, B. J. Gurley, B. L. Ketel, and S. R. Abul-Ezz, "Herbal supplements: a potential for drug interactions in transplant recipients," Transplantation, vol. 71, no. 2, pp. 239-241, 2001.

[111] E. Ernst, "St John's Wort supplements endanger the success of organ transplantation," Archives of Surgery, vol. 137, no. 3, pp. 316-319, 2002. 
[112] C. R. D. Colson and M. E. De Broe, "Kidney injury from alternative medicines," Advances in Chronic Kidney Disease, vol. 12, no. 3, pp. 261-275, 2005.

[113] A. Lehnhardt and M. J. Kemper, "Pathogenesis, diagnosis and management of hyperkalemia," Pediatric Nephrology, vol. 26, no. 3, pp. 377-384, 2011.

[114] A. C. J. Cowan, E. G. Gharib, and M. A. Weir, "Advances in the management of hyperkalemia in chronic kidney disease," Current Opinion in Nephrology and Hypertension, vol. 26, no. 3, pp. 235-239, 2017.

[115] B. A. Mueller, M. K. Scott, K. M. Sowinski, and K. A. Prag, "Noni juice (Morinda citrifolia): hidden potential for hyperkalemia?" American Journal of Kidney Diseases, vol. 35, no. 2, pp. 310-312, 2000.

[116] S. Mohamed, "Functional foods against metabolic syndrome (obesity, diabetes, hypertension and dyslipidemia) and cardiovasular disease," Trends in Food Science \& Technology, vol. 35, no. 2, pp. 114-128, 2014.

[117] L. Menati, A. Meisami, and M. Zarebavani, "The potential effects of dietary flavones on diabetic nephropathy; a review of mechanisms," Journal of Renal Injury Prevention, vol. 9, no. 2, p. e09, 2020.

[118] A. Bower, S. Marquez, and E. G. de Mejia, "The health benefits of selected culinary herbs and spices found in the traditional Mediterranean diet," Critical Reviews in Food Science and Nutrition, vol. 56, no. 16, pp. 2728-2746, 2016.

[119] M. Asif, "Nephroprotective potential of medicinal plants and herbal medicines: a review on natural nephroprotective agents," Young Scientist-Tomorrows Science Begins Today, vol. 2, no. 1, 2018.

[120] L. Abdelhamid, X. Cabana-Puig, and B. Swartwout, "Vitamin A deficiency deteriorates lupus nephritis," American Association of Immunologists, vol. 206, 2021.

[121] S. F. Rapa, B. R. Di Iorio, P. Campiglia, A. Heidland, and S. Marzocco, "Inflammation and oxidative stress in chronic kidney disease-potential therapeutic role of minerals, vitamins and plant-derived metabolites," International Journal of Molecular Sciences, vol. 21, no. 1, p. 263, 2020.

[122] D. S. Fettouh, D. S. Saif, S. F. El Gazzar, and A. A. Sonbol, "Study the relationship between vitamin A deficiency, T helper 17, regulatory $\mathrm{T}$ cells, and disease activity in patients with systemic lupus erythematosus," Egyptian Rheumatology and Rehabilitation, vol. 46, no. 4, pp. 244-250, 2019.

[123] A. Crozier, M. N. Clifford, and H. Ashihara, Plant Secondary Metabolites: Occurrence, Structure and Role in the Human Diet, John Wiley \& Sons, 2008.

[124] K. R. R. Rengasamy, H. Khan, S. Gowrishankar et al., "The role of flavonoids in autoimmune diseases: therapeutic updates," Pharmacology \& Therapeutics, vol. 194, pp. 107-131, 2019.

[125] J. A. Beto, K. Schury, and V. Bansal, "Strategies to promote adherence to nutritional advice in patients with chronic kidney disease: a narrative review and commentary," International Journal of Nephrology and Renovascular Disease, vol. 9, p. 21, 2016.

[126] M. G. Vervloet and A. J. van Ballegooijen, "Prevention and treatment of hyperphosphatemia in chronic kidney disease," Kidney International, vol. 93, no. 5, pp. 1060-1072, 2018.

[127] C. P. Kovesdy, "Management of hyperkalaemia in chronic kidney disease," Nature Reviews Nephrology, vol. 10, no. 11, pp. 653-662, 2014.

[128] K. Picard, "Potassium additives and bioavailability: are we missing something in hyperkalemia management?" Journal of Renal Nutrition, vol. 29, 2018.
[129] D. J. Clegg and K. M. Hill Gallant, "Plant-based diets in CKD," Clinical Journal of the American Society of $\mathrm{Ne}$ phrology, vol. 14, no. 1, pp. 141-143, 2019.

[130] K. E. Lynch, R. Lynch, G. C. Curhan, and S. M. Brunelli, "Prescribed dietary phosphate restriction and survival among hemodialysis patients," Clinical Journal of the American Society of Nephrology, vol. 6, no. 3, pp. 620-629, 2011.

[131] N. Noori, J. J. Sims, J. D. Kopple et al., "Organic and inorganic dietary phosphorus and its management in chronic kidney disease," Iranian Journal of Kidney Diseases, vol. 4, no. 2, pp. 89-100, 2010.

[132] S. Joshi, S. Hashmi, S. Shah, and K. Kalantar-Zadeh, "Plantbased diets for prevention and management of chronic kidney disease," Current Opinion in Nephrology and Hypertension, vol. 29, no. 1, pp. 16-21, 2020.

[133] B. Goldner, "Six week raw vegan nutrition protocol rapidly reverses lupus nephritis: a case series," International Journal of Disease Reversal and Prevention, vol. 1, no. 1, 2019. 